\title{
Dairesel Silindir Etrafındaki Akış Yapısının Kontrü Için Hibrit Control Elementi
}

\author{
${ }^{1 *}$ Engin Pınar ${ }^{2}$ Tahir Durhasan ${ }^{1}$ Göktürk M.Özkan ${ }^{1}$ Umutcan OLMUŞ ${ }^{1}$ Hüseyin Akıllı ${ }^{1}$ Beşir Şahin \\ ${ }^{1}$ Faculty of Ceyhan Engineering, Department of Mechanical Engineering Çukurova University, Turkey \\ ${ }^{2}$ Faculty of Aeronautics and Astronautics, Department of Aerospace Engineering, Adana Science and Technology \\ University, Turkey
}

\section{Özet}

Bu çalışmada, küt cisimlerin iyi bir örneği olan silindirin etrafında oluşan akış yapısı hibrit kontrol elemanı yardımı ile kontrol edilmeye çalışılmıştır. Deneyler iç yalın silindir çapına, $\mathrm{D}_{\mathrm{i}}=50 \mathrm{~mm}$, bağlı Reynolds sayısının $R_{\mathrm{Di}}=10000$ değeri için Parçaçık Görüntülemeli Hız ölçme Tekniği (PIV) kullanılarak gerçekleştirilmiştir. Hibrit kontrol elemanı, geçirgenlik oranı, $\beta_{\mathrm{s}}=0.5$, olan delikli silindir ve geçirgenlik oranı, $\beta_{\mathrm{p}}=0$, olan üç plaka kullanılarak oluşturulmuştur. Plakaların en değerleri ise $L_{p}=1$ ve $L_{p}=1$ 'in $3 / 4$ 'ü olacak şekilde seçilmiştir. İç silindir çapının delikli dış silindirin çapına oranı, $\mathrm{D}_{\mathrm{i}} / \mathrm{D}_{\mathrm{d}}=0.5$, ve plakalar arası açı, $\theta=120^{\circ}$, olarak sabit tutulmuştur. Plakalardan biri iç silindirin ön durma noktasına gelecek şekilde konumlandırılmış, serbest akış ile yapmış olduğu açı değeri, $\alpha=0^{\circ}, 30^{\circ}$ ve $60^{\circ}$ (plaka-akış açısı) için üç farklı açı değerinin etkisi incelenmiştir. Sonuçlar, zaman ortalaması alınmış akış karakteristiklerini ifade eden girdaplar, akım çizgileri ve boyutsuz türbülans kinetik enerji değerleri için yalın silimdir durumu ile karşılaştırılmalı olarak verilmiştir. Hibrit kontrol elemanın silindir çiftinin ara bölgesinde oluşan akış yapısını kontrol etmede başarılı olduğu belirlenmiştir. Plaka en değeri, $L_{p}=1$ ve $L_{p}=1$ 'in 3/4' ü için elde edilen türbülans istatistik değerleri bir birine yakındır. Bununla birlikte ara bölgede ki hem akış yapısı hem de türbülans istatistikleri birlikte incelendiği zaman daimi olmayan girdapları kontrol etmede plaka en değeri, $L_{p}=1$ 'in en etkili parametre olduğu belirlenmiştir.

Anahtar Kelimeler: Ayırıcı Plaka, Dairesel silindir, Pasif Akış Kontrol, TKE

\section{Hybrid Control Element for Controlling Flow Structure Around a Circular Cylinder}

\begin{abstract}
In this work, control of the flow around a circular cylinder was studied using a hybrid control element. Particle image velocimetry (PIV) was used for the experiments and performed at a Reynolds number of $R e_{D i}=10000$ based on the inner cylinder diameter of $D_{i}=50 \mathrm{~mm}$. Hybrid control element consists of a perforated cylinder having a porosity of $\beta \mathrm{s}=0.5$, and three plates covering the bare cylinder. The width values were chosen to be $L p=1$ ve $L p=3 / 4$. The ratio of the inner cylinder to outer cylinder and the angle between the plates were taken constantly as $\mathrm{Di} / \mathrm{Dd}=0.5$ and $\theta=120^{\circ}$, respectively. One of the plates was located at the front stagnation point of the cylinder and the effect of plate-to-free stream flow angle was investigated for $\alpha=0^{\circ}$, $30^{\circ}$ ve $60^{\circ}$. The results were presented by means of time-averaged flow characteristics such as streamlines, normalized turbulent kinetic energy by comparing with the bare cylinder. It was revealed that the hybrid
\end{abstract}

*Corresponding author: Address: Faculty of Ceyhan Engineering, Department of Mechanical Engineering Çukurova University, Turkey, cukurovauniversitesi@hs01.kep.tr 01330, Sarıcam / Adana, TURKEY 


\section{E. PINAR et al./ISITES2019 SanliUrfa - Turkey}

control element is successful on controlling the flow within the annular region of the inner-outer cylinder. The turbulent statistics evaluated are similar for $L p=1$ ve $L p=3 / 4$. However, it is concluded that the plate width of $\mathrm{Lp}=1$ is the most effective parameter when considering both the flow structure and turbulent statistics in the annular region.

Key Words: Circular cylinder, TKE, Passive flow control, Splitter plate

\section{Giriş}

Küt cisimler etrafındaki akış yapısına ait çalışmalar, çok farklı geometrilere sahip küt cisimler bulunmasına rağmen dairesel, kare, elips gibi kesitleri olan silindirik formdaki cisimler üzerine yoğunlaşmıştır. Silindirik cisimler etrafındaki akışlar köprü ayakları, ısı değiştiricileri, binalar, bacalar, soğutma kuleleri, direkler, deniz üzerine yapılan petrol arama istasyonları gibi uygulamaları içermektedir. Akış, silindir gibi bir cismi geçtiğinde silindirin alt ve üst durma noktalarından arka arkaya girdaplar kopmakta ve bilinen Karman girdap caddelerini oluşturmaktadır. Kopan bu girdaplar birbirine zıt yönde dönerek silindirin ard izinde aşağı akım yönünde ilerlemektedirler. Girdapların frekansı boyutsuz Strouhal sayısı ile ifade edilmekte olup hızın, silindir çapının ve Reynolds sayısının fonksiyonudur (Roshko 1955). Girdap kaynaklı titreşimler 1940 yılında Tacoma Köprüsünün yıkılmasından sonra araştırmacılar için ilgi çekici bir konu haline gelmiştir. Köprünün tabliyesi akış alanında duran bir küt cisimdir. Silindirik cismin etrafından kopan girdapların cisim üzerinde neden olduğu titreşimin frekansı ile cismin doğal frekansının üst üste gelerek kenetlenmesi (lock-in) sonucu yıkıcı etkileri olabilir (Blevins 2001). Dolayısı ile birçok mühendislik uygulamasında cisimler üzerine etki eden girdap kaynaklı titreşimlerin bilinmesi tasarım açısından önem arz etmektedir. Charles-Henri Bruneau ve Iraj Mortazavi (2006) bir boru kesiti çevresindeki gözenekli kılıfın etkilerini sayısal (numerik) olarak incelemişlerdir. Gözlemlerini, gerçek deniz şartlarına yakın olan $\mathrm{Re}=15000$ ve $\mathrm{Re}=150000$ 'de gerçekleştirmişlerdir. Gözenekli katmanın varlığının sınır tabakasındaki kayma (shear) etkilerini azalttığını ve böylece girdap kopmasını olumlu yönde değiştirdiğini belirtmişlerdir. Buna ek olarak, bu pasif kontrol yönteminin $C_{\text {Lrms }}$ değerini $\mathrm{Re}=15000$ için \%55'e kadar, $\mathrm{Re}=150000$ için ise \%72'ye kadar düşürdüğünü bulmuşlardır. Galvao vd. (2008), dairesel bir silindir etrafındaki akışı kontrol etmek, girdap kaynaklı titreşimleri azaltmak ve sürüklenme katsayısını düşürmek amacıyla silindir etrafına yerleştirilmiş kanatçıklar kullanmışlardır. Deneysel olarak gerçekleştirdikleri bu çalışmayı, bir kuvvet ölçüm sistemi ve Parçacık Görüntülemeli Hız Ölçme Tekniğini (PIV) senkronize etmek suretiyle gerçekleştirmişlerdir. Önce iki, daha sonra dört adet kullanılan kanatçıklar yardımıyla silindir üzerinde oluşan titreşimlerin tamamen yok edildiği ve alt kritik Reynolds değerleri için sürükleme katsayısının $\mathrm{Cd}=0.5$ 'e kadar düşürülebileceği sonuçlarına ulaşmışlardır. Choi vd. (2008) akış kontrolü ile ilgili oldukça kapsamlı bir çalışma yaparak, şimdiye kadar çalışılan akış kontrol yöntemlerini derlemiştir. Çalışmalarında, akış kontrolünün pasif, aktif açık-devre ve aktif kapal1-devre olmak üzere üç farklı yolla mümkün olduğunu belirtmiş ve uygulama örnekleri ile birlikte yapılan çalışmaları ayrıntılı olarak açıklamışlardır. Lee ve Ko (2009) bir uçak kanadı modelinin arkasına yerleştirilmiş olan delikli Gurney-model kanatçığın arkasındaki akışı PIV ölçme yöntemini kullanarak Reynolds sayısı $5.3 \times 10^{4}$ için incelemişlerdir. Bu çalışma sırasında, 20x20x $85 \mathrm{~cm}$ ölçülere ve $\% 0.9$ değerindeki bir türbülans yoğunluğuna sahip olan rüzgar tüneli kullanmışlardır. Deneyde kullanılan kanatçıklardaki delik çaplarını $1.6 \mathrm{~mm}, 3.2 \mathrm{~mm}$ ve $4.8 \mathrm{~mm}$ seçerek geçirgenlik oranlarını \%23, 
$\% 40$ ve $\% 50$ olarak belirlemişlerdir. PIV ölçüm verilerini aynı zamanda kuvvet dengesi ve yüzey basıncı verileri ile desteklemişlerdir. Kanatçıkların taşıma kuvvetini olumlu yönde etkilediğini gözlemlemişlerdir, ancak aynı zamanda kanatçığa sahip olan modelin arkasındaki girdap genişliği ve düzensizliğinin de kanatçık kullanılmayan modele göre arttığını da gözlemlemişlerdir. Geçirgenlikten dolayı oluşan tek ve çift jet (sırasıyla \%23 ve \%40 açıklık oranına) akışlarının kanatçığın akış yönü tarafında ani olarak ters akışla karışması sayesinde girdap kopma sürecinin bozulduğunu görmüşlerdir. Nicolas vd. (2012) bir kuşun tüyünden esinlenilerek doğayı yansitan bir yaklaşımda bulunan bir pasif kontrol aracı üzerine deneysel çalışmalar yapmışlardır. İki adet alüminyum kare kesit silindire öz-uyarlanan kanatçıkları uygulamışlar ve böylece kanatçıkların akış yönünde kendiliğinden hareket etmesini sağlamışlardır. Deneylerini açık çevrim bir rüzgar

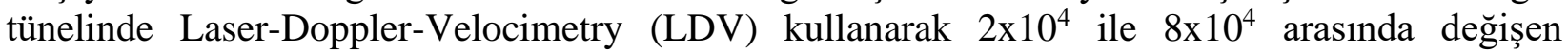
Reynolds sayıları için gerçekleştirmişlerdir. Bal peteği ve belirli çerçeve yapılarının yardımıyla rüzgar tünelinde çok düşük bir türbülans yoğunluğu değeri elde etmeyi başarmışlardır (<\%0.4). Sonuç olarak geniş bir Reynolds sayısı aralığında ortalama olarak \%22 civarında bir sürüklenme katsayısı azalması elde etmişlerdir. Bunun yanı sıra, düşük Reynolds sayılarında, her iki kanatçı̆̆ın dönme frekanslarının doğal girdap kopma frekansından yüksek olduğunu belirlemiş̧lerdir. Diğer yandan, yüksek Reynolds sayılarında, bu kanatçıkların dönme frekanslarının doğal girdap kopma frekansının yaklaşık yarısı kadar düşük olduğunu ortaya koymuşlardır. Pinar vd. (2014) geçirgenlik oranının $\beta=0.5-0.6$ değerleri aralığında iç silindir ardında oluşan daimi olmayan girdapların etkin bir şekilde kontrol edildiğini belirlemişlerdir. Daha düşük geçirgenlik oranlarında dış silindirin ardındaki türbülanslılıkta artış olmasına karşın elde edilen değerler dış silindirin bulunmadığı sadece iç silindirin bulunduğu duruma nazaran daha düşük çıkmıştır. Ayrıca türbülans istatistiklerin (Reynolds gerilmesi, Türbülans Kinetik Enerjisi gibi) en yüksek değere ulaştığı yer dış silindirden daha uzak noktalara kaymakta olduğunu ifade etmişlerdir. Geçirgenlik oranının $\beta=0.6$ 'dan daha büyük değerlerinde dış silindirin iç silindir üzerine etkisi azalmıştır. Buna bağlı olarak dış silindirin hemen ardında daimi olmayan akış yapısı oluşmuştur. Çap oranının düşük değerlerinde ise dış silindirin ardında türbülanslılıkta düşme olmasına karşın dış silindirle iç silindir arasındaki bölgede daimi olmayan akışın oluştuğunu belirlemişlerdir. Çap oranının $\mathrm{D}_{\mathrm{i}} / \mathrm{D}_{\mathrm{d}}=0.8$ değerinden itibaren iç silindir ile diş silindirin tek silindir gibi davranmakta olduğunu ve ard izinde türbülanslılığın arttığını tespit etmişlerdir. Durhasan vd. (2018) test modelleri olarak farklı gözeneklere sahip delikli silindirleri kullanmışlardır. Gözenekliliğin akış üzerindeki etkisini incelemek amacıyla 8 farklı gözenekliğe sahip, $\beta=0.25,0.3,0.4,0.45,0.5,0.6,0.7$ ve 0.8 silindirleri kullanmışlardır. Kullanılan delikli silindirlerin çapını $100 \mathrm{~mm}$ ve yapılan deneysel çalışmalarda Reynolds sayısını 10000 almışlardır. Gözenekliliğin arttırılmasıyla birlikte akış dalgalanmalarının arka bölgede büyük ölçüde azaldığını gözlemlemişlerdir. Durhasan vd. (2019), dış silindirin ve gözenekliliğin silindirin girdap mekanizması üzerindeki etkisini ortaya çıkarmak için yalın silindir ve delikli dış silindir arasındaki bölgedeki akış karakteristiklerini PIV tekniğini kullanarak deneysel olarak incelemişlerdir. Deneyler Reynolds sayısının 5000, geçirgenlik oranının 0.3, 0.4, 0.5, 0.6, 0.7 ve çap oranının $\mathrm{D}_{\mathrm{i}} / \mathrm{D}_{\mathrm{d}}=0.4,0.5,0.6$ olduğu durumlar için için gerçekleştirilmiştir. Tüm çap oranlarında, geçirgenlik oranının 0,5 ve daha küçük olduğu durumlarda iç silindir ile dış silindir arasında kalan bölgede girdap oluşumunun kısıtlandığı görülmüsştür. Ayrıca silindirlerin sürükleme katsayısının sadece yalın silindirin kullanıldığı duruma kıyasla delikli dış silindir kullanıldığında önemli ölçüde azaldığı bulunmuştur. Bununla birlikte dış silindirin kullanıldığı 
durumdaki sürüklenme katsayısı akışa maruz kalan alanı genişlettiğinden tüm durumlar için yalın silindirden daha yüksek olduğunu belirlemişlerdir.

\section{Gereç ve Yöntem}

$\mathrm{Bu}$ çalışma, Çukurova Üniversitesi, Makine Mühendisliği Bölümü, Akışkanlar Mekaniği Laboratuarında kurulu olan kapalı devre açık su kanalında gerçekleştirilmiştir. Deney düzeneğine ait şematik gösterimi şekil 1a'da görülmektedir. Deneyler su kanalına yerleştirilen bir platform üzerinde yapılmaktadır. Deneylerde kullanılan şeffaf platform sayesinde delikli plaka ve yalın silindirin etrafına eş merkezli olarak yerleştirilen delikli silindir sabitlenmiştir. Bu platformun uzunluğu $2300 \mathrm{~mm}$, genişliği $980 \mathrm{~mm}$ ve platformun tabanının su kanalının tabanından yüksekliği ise üsteki pleksi-glass tabaka ile birlikte $220 \mathrm{~mm}$ olacak şekilde ayarlanmıştır. Deneyler boyunca su derinliği $\mathrm{H}_{\mathrm{W}}=330 \mathrm{~mm}$ 'de sabit tutulmuştur. Burada verilen deney sonuçları serbest su hızının $U_{\infty}=100 \mathrm{~mm} / \mathrm{s}$ değeri ve Reynolds sayısının $\mathrm{Re}=10000$ değeri için yapılmıştır. Elde edilen hız alanındaki vektörlerin ağ ölçüleri üst görünüş $1.488 \times 1.488 \mathrm{~mm}^{2}$ dir. Üst görünüş için $\mathrm{x}$ ve y yönünde toplam 7,227 (99x73) adet vektör hesaplanmıştır. Hız alanının boyutu üst görünüş için $150.8 \times 201.2 \mathrm{~mm}^{2}$ dir. Geçirgenlik oranı $(\beta)$ olarak adlandırılan boyutsuz ifade, silindir/plaka yüzeyindeki delikli alanların toplamının silindirin/plaka toplam yüzey alanına oranı olarak ifade edilmektedir. Delikler eş kenar üçgen oluşturacak şekilde birer delik kaydırılarak ayarlanmıştır. Çap oranı, $\mathrm{D}_{\mathrm{i}} / \mathrm{D}_{\mathrm{d}}$ ise yalın iç silindirin çapının delikli dış silindirin çapına oranı olarak belirlenmiştir. Deneyler çap oranı, $\mathrm{D}_{\mathrm{i}} / \mathrm{D}_{\mathrm{d}}=0.5$ delikli silindir geçirgenlik oranı $\beta_{\mathrm{s}}=0.5$, delikli plaka geçirgenlik oran, $\beta_{p}=0$, plakaların en değerleri ise $L_{p}=1$ ve $L_{p}=1$ 'in $3 / 4$ ' $\ddot{\text { u olacak }}$ şekilde seçilmiştir. Hibrit elemanı oluşturan plakalar arası açı, $\theta=120^{\circ}$, olarak sabit tutulmuştur. Şekil 1b'de de görüldüğü üzere plakalardan biri iç silindirin ön durma noktasına gelecek şekilde konumlandırılmış, bu plakanın serbest akış ile yapmış olduğu açı değeri ise $\alpha=0^{\circ}, 30^{\circ}$ ve $60^{\circ}$ olarak ayarlanmış ve üç farklı açı değerinin etkisi incelenmiştir. PIV deneyleri esnasında su yüksekliği $330 \mathrm{~mm}$, ölçüm düzleminin yüksekliği ise $165 \mathrm{~mm}$ olarak ayarlanmıştır. Parçacık görüntülemeli hız ölçme yönteminde kullanılan matematiksel ifadeler ve gerekli bilgiler Westerweel vd. (1993) ve Adrian vd. (1991)'in çalışmalarında verilmiştir. PIV yönteminde katı parçacıkların üniform olarak dağılmaması, görüntü alınması anında partiküllerin üst üste gelmesi, partiküllerin lazer düzleminden dişarıya doğru hareket etmesi, düzlem dışındaki partiküllerin lazer düzlemine girmesi, hız vektörlerinin hesaplandığı alanın boyutu, elektronik ve optik gürültülerden kaynaklanan toplam belirsizlik değerinin $\% 2$ den az olduğunu belirtilmektedir. 


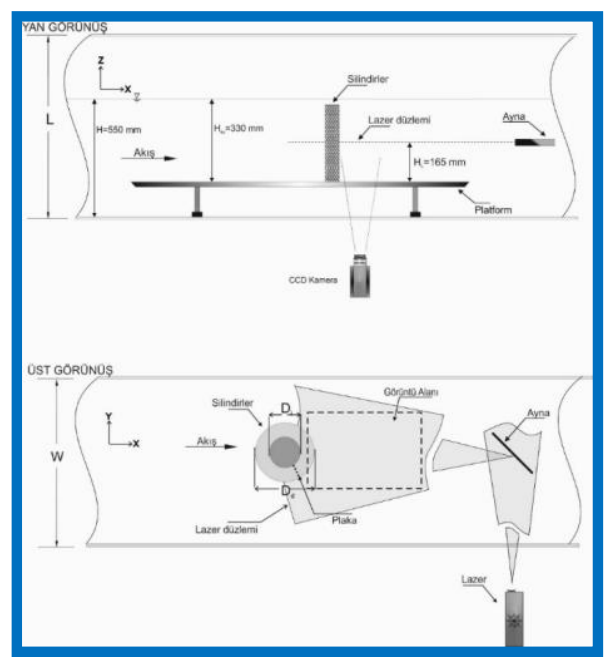

Şekil 1a. Deney düzeneğinin şematik gösterimi

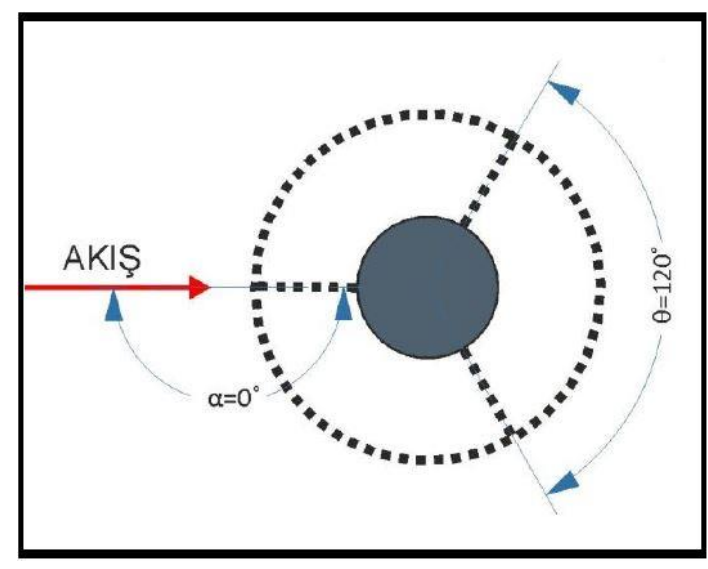

Şekil 1b. Üç plaka durumu için plaka açısı

Üç plaka ve delikli silindirin bir araya getirilmesi ile oluşturulan hibrit kontrol elamanı, $50 \mathrm{~mm}$ çapa sahip dairesel silindir ile eş merkezli olarak yerleştirilmiştir. Dairesel silindirden kopan girdapların neden olduğu daimi olmayan akış yapısı hibrit kontrol elemanı yardımı ile kontrol altına alınmaya çalışılmıştır. Şekil 2'de birinci resimde (şekil 2a) yalın silindir etrafında oluşan akış yapısına ait boya ile görselleştirme deney sonucu görülmektedir. Yalın silindirin alt ve üst ayrılma noktalarından arka arkaya sira ile kopan girdaplar belirli bir frekansta S hareketi yaparak aşağı akım yönünde ilerleyen Karman Girdap caddelerinin oluşmasına neden olmaktadır. Zaman ortalamalı akım çizgileri $\langle\psi\rangle$ ve girdap eş düzey eğrileri, $\langle\omega\rangle$ sırası ile şekil $2 \mathrm{~b}$ ve şekil 2 c'de görülmektedir. Şekillerde kontrol elemanın olmadığı durumda yalın silindir ard izi bölgesinde literatür ile uyumlu sonuçların elde edildiği belirlenmiştir. Akım çizgilerinden biri saat yönünde, $F_{1}$ diğeri ise saatin tersi yönde dönen, $F_{2}$ girdap odak noktalarının birbirleri ile simetrik olarak oluştukları görülmektedir. Aşağı akım yönünde silindirin yüzeyinden itibaren yaklaşık olarak 1.27D sonra silindir çevresinden ayrılan akış birleşerek durma noktasının oluşmasına neden olmaktadır. Şekil 2c'de görülen zaman ortalamalı girdap eş düzey eğrilerinin 
minimum girdap konturunun değeri $\pm 21 / \mathrm{s}$ ve artım ise yine $21 / \mathrm{s}$ 'dir. Yalın silindirden kopan girdapların maksimum değerinin \pm 28 1/s olduğu şekil altında verilen ölçekten anlaşılmaktadır.

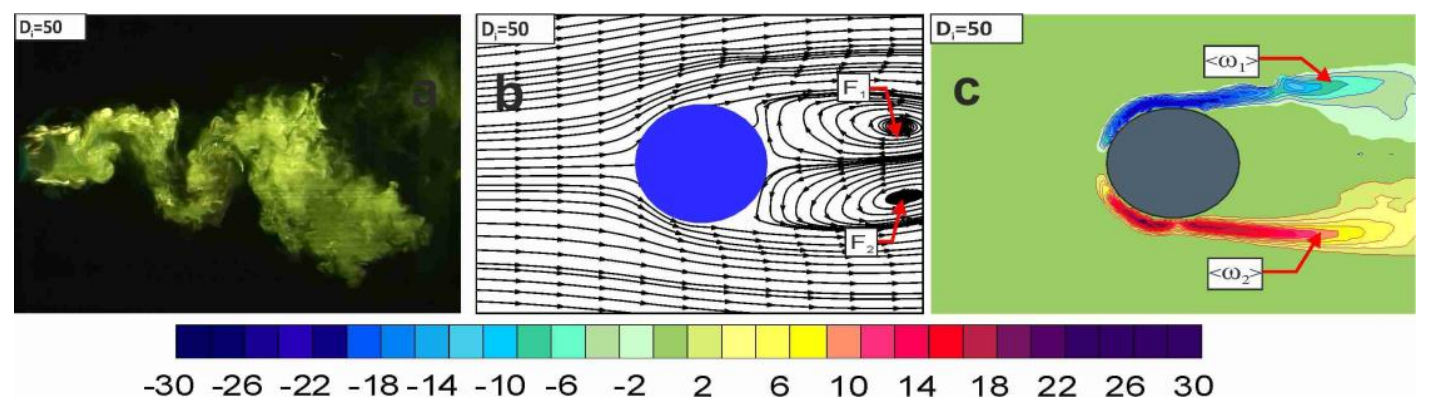

Şekil 2. Akış alanında iç silindirin bulunduğu durum için elde edilen zaman ortalama akım çizgileri $\langle\psi\rangle$ ve zaman ortalama girdap eş düzey eğrileri, $\langle\omega\rangle$ görülmektedir. Minimum girdap konturunun değeri $\pm 21 / \mathrm{s}$ ve artım ise yine $21 / \mathrm{s}^{\prime}$ dir.

Akış alanı içerisinde sadece geçirgenlik oranı, $\beta_{\mathrm{s}}=0.5$ olan delikli dış silindirin bulunduğu durum ile yalın silindirin etrafında delikli silindir yerleştirilmesi sonucu elde edilen PIV sonuçları sırası ile Şekil 3'de sunulmuştur. Belirtilen durumların incelenmesindeki amaç hibirit kontrol elemanın akış yapısı üzerine olan etkilerini karşılaştırabilmektir. Şekil 3a'da akış alanı içerisinde sadece geçirgenlik oranı, $\beta_{\mathrm{s}}=0.5$ olan delikli silindir bulunduğu durumda akım çizgileri, $<\psi>$ resimlerinde silindirin iç kısmında alt ve üst ayrılma noktaları civarında $F_{1}$ ve $F_{2}$ ile gösterilen iki adet sirkülasyon odak noktası bulunmaktadır. Şekil 3b'de ise delikli silindirin içerisine girmekte olan serbest akış ile silindirin arkasından çıkan akışın neden olduğu küçük ölçekli düşük şiddetli girdapların oluştuğunu görmekteyiz. Bu durum diş silindirin geçirgenlik oranın, $\beta_{\mathrm{s}}=0.5$ olmasına rağmen delikli silindirin iç bölgesine yüksek momentuma sahip akışın girdiğinin göstergesidir. Şekil 3c ve 3d'de, kontrol elemanı olarak sadece delikli dış silindirin bulunduğu durumda elde edilen sonuçlar görülmektedir. Şekil 3c'de iç silindirden ayrılan akış yalın silindir durumunda olan akışa benzer şekilde (şekil 2 b) hemen hemen simetrik iki adet sirkülasyon odak noktasının oluşmasına neden olmaktadır. Girdap konturlarını incelediğimiz zaman iç silindirin ard izinde yalın silindir durumunda elde edilen girdaplara benzer şekilde büyük ölçekli pozitif ve negatif iki adet büyük ölçekli girdabın oluştuğu görülmektedir. Bu girdapların oluşması delikli dış silindirin silindir çiftinin ara bölgesinde oluşan girdapları kontrol etmede yetersiz kaldığının bir göstergesidir. Şekil 3d'de her iki durumda da delikli dış silindirin ard izinde w3 ve w4 ile gösterilen düşük şiddetli geniş ölçekli zaman ortalamalı girdaplar oluşmaktadır. Sadece delikli diş silindirin kontrol elemanı olarak kullanılması durumunda ayrılmış akışın neden olduğu w1 ve w2 ile gösterilen girdapların şiddetinin yalın silindir için elde edilen $\pm 281 / \mathrm{s}$ değerinden \pm 10 1/s değerine azaldığ 1 şekil altlarında verilen girdap şiddeti renk ölçeklerinden anlaşılmaktadır. Şekil 2 ve şekil 3 birbirleri ile karşılaştırmalı olarak incelendiği zaman kontrol elemanı olarak sadece delikli dış silindir kullanılmasının girdap şiddetlerini azaltmada etkili olduğu belirlenmiştir. 

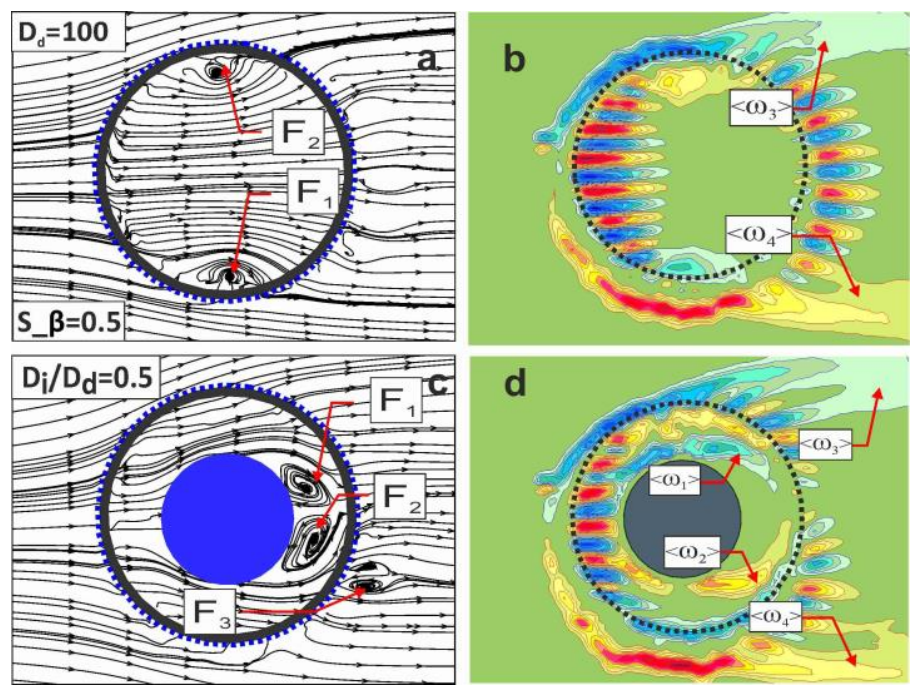

Şekil 3. Geçirgenlik oranı $\beta_{\mathrm{s}}=0.5$ delikli dış silindirin bulunduğu durum ve yalnızca iç- diş silindirin bulunduğu durum için elde edilen zaman ortalama akım çizgileri $\langle\psi\rangle$ ve zaman ortalama girdap eş düzey eğrileri, $<\omega>$ görülmektedir. Minimum girdap konturunun değeri $\pm 21 / \mathrm{s}$ ve artim ise $\pm 21 / \mathrm{s}^{\prime}$ dir.

Şekil 4'de Çap oranının, $\mathrm{D}_{\mathrm{i}} / \mathrm{D}_{\mathrm{d}}=0.5$, diş silindir geçirgenlik oranının, $\beta_{\mathrm{s}}=0.5$, plaka geçirgenlik oranı, $\beta_{\mathrm{p}}=0$ ve plakalar arası açı, $\theta=120^{\circ}$, değeri için şekil $4 \mathrm{a}$, $4 \mathrm{c}$ ve $4 \mathrm{e}$ plaka eninin $\mathrm{L}_{\mathrm{p}}=1$ şekil $4 \mathrm{~b}, 4 \mathrm{~d}$ ve $4 \mathrm{f}$ ise plaka eninin $\mathrm{L}_{\mathrm{p}}=1$ 'in 3/4'ü olduğu durumda tüm plaka-akış açısı değeri, $\alpha=0^{\circ}, 30^{\circ}$ ve $60^{\circ}$ için üç farklı açı değerinin etkisi incelenmiştir. Her iki sütunda da zaman ortalama akım çizgileri, $\left\langle\psi>\right.$ görülmektedir. Şekil $4 \mathrm{a}, 4 \mathrm{c}$ ve $4 \mathrm{e}$ plaka eninin $\mathrm{L}_{\mathrm{p}}=1$ olduğu durumda, tüm plaka-akış açısı, $\alpha$ değeri için silindir çiftinin ara bölgesine giren akışkan, plakalar üzerinde delik bulunmadığı için plakalara çarparak delikli dış silindirin dışına yönelmektedir. Bu durumun sonucu olarak ise yalın silindirin ard izinde şekil 2 ve şekil 3'de $F_{1}$ ve $F_{2}$ ile gösterilen girdap odak noktaları oluşmamaktadır. Delikli silindirin dışında ise silindirlerin ara bölgesinden dışarı yönelen akışın neden olduğu $\mathrm{F}_{3}$ ve $\mathrm{F}_{4}$ ile gösterilen silindir çiftinin tüm ard izini kapsayan girdap odak noktaları oluşmaktadır. Şekil $4 b$, 4 d ve $4 f$ plaka eninin $L_{p}=1$ 'in 3/4' ü olduğu durumda plaka-akış açısı, $\alpha$ değerleri için silindir çiftinin ara bölgesine giren akışkan plakaların geçirgenlik oranı, $\beta_{\mathrm{p}}=0$ olmasına rağmen plaka ile delikli silindir arasında kalan dar aralıktan geçmekte ve plakalar arasında $F_{1}$ ve $F_{2}$ girdap odak noktalarının oluşmasına neden olmaktadır. Ayrıca silindir çiftinin ard izinde delikli silindirin diş yüzeyinden uzakta aşağı akım yönünde $F_{3}$ ve $F_{4}$ girdap odak noktalarının oluştuğu belirlenmiştir. Akım çizgileri sonuçlarına göre ortalama akış yapısı incelendiği zaman girdap odak noktalarının oluşumuna göre plaka eninin, $\mathrm{L}_{\mathrm{p}}=1$ olması durumunda elde edilen akış yapısı hibrit kontrol elemanın akış üzerinde etkili olduğunu göstermektedir. 


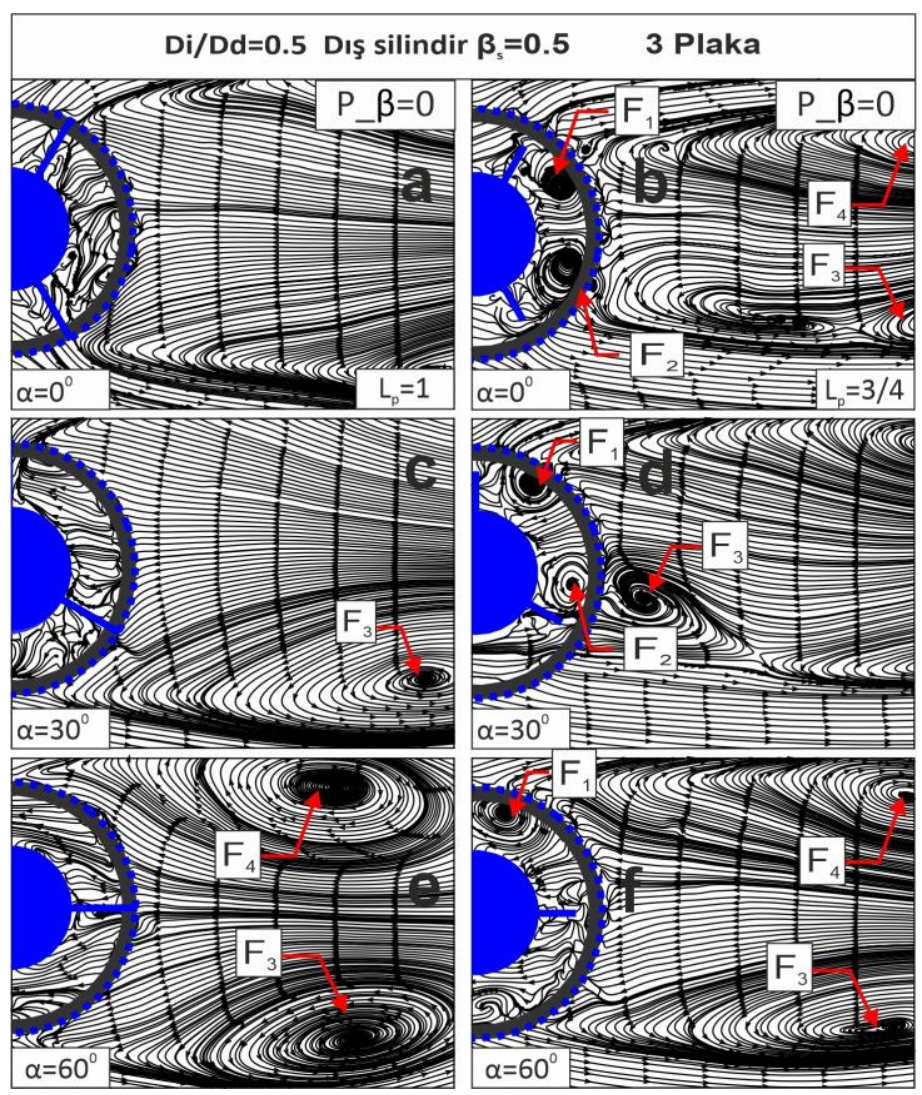

Şekil 4. Çap oranının, $D_{\mathrm{i}} / \mathrm{D}_{\mathrm{d}}=0.5$, dış silindir geçirgenlik oranının, $\beta_{\mathrm{s}}=0.5$, plaka geçirgenlik oranının, $\beta_{p}=0$, plakalar arası açının, $\theta=120^{\circ}$, plaka eninin $L_{p}=1$ ve $L_{p}=1$ 'in 3/4'ü olduğu durumda farklı plaka-akış açısı, $\alpha$ değerleri için zaman ortalama akım çizgileri $\langle\psi\rangle$.

Çap oranının, $\mathrm{D}_{\mathrm{i}} / \mathrm{D}_{\mathrm{d}}=0.5$, dış silindir geçirgenlik oranının, $\beta_{\mathrm{s}}=0.5$, plaka geçirgenlik oranı, $\beta_{\mathrm{p}}=0$ ve plakalar arası açı, $\theta=120^{\circ}$ değeri için birinci ve ikinci sütunda sırası ile plaka enin plaka eninin $L_{p}=1$ ve $L_{p}=1$ 'in 3/4'ü olduğu durumda farklı plaka-akış açıları, $\alpha$ için zaman ortalama girdap eş düzey eğrileri, $<\omega>$ görülmektedir. Minimum girdap konturunun değeri $\pm 21 / \mathrm{s}$ ve artım ise $\pm 21 /$ s'dir. $^{2}$.

Şekil 5'de Çap oranının, $D_{i} / D_{d}=0.5$, diş silindir geçirgenlik oranının $\beta_{\mathrm{s}}=0.5$ ve plaka eninin $\mathrm{L}_{\mathrm{p}}=1$ olduğu durumda farklı plakalar arası açı, $\theta$ ve iki farklı plaka geçirgenlik oranı, $\beta_{\mathrm{p}}=0$ ve $\beta_{\mathrm{p}}=0.5$ için zaman ortalama girdap eş düzey eğrileri, $\langle\omega\rangle$ görülmektedir. Minimum girdap konturunun değeri $\pm 21 / \mathrm{s}$ ve artım ise $\pm 21 / \mathrm{s}$ 'dir. Plaka eninin, $\mathrm{L}_{\mathrm{p}}=1$ değeri için silindir çiftinin ara bölgesinde minimum girdap konturu ve artırım değerine göre yalın silindirin ard izinde oluşan şekil 2 ve şekil 3'de $\omega_{1}$ ve $\omega_{2}$ ile gösterilen girdapların oluşmadığ eninin, $L_{p}=1$ 'in $3 / 4$ ' $\ddot{u}$ olduğu durumda $\omega_{1}$ ve $\omega_{2}$ ile gösterilen girdapların değişen plaka-akış açıs1 değerleri için plakaların yukarı akım yönünde oluştuğu ancak şiddetinin ise $\pm 101 / \mathrm{s}$ değerlerine azaldığ 1 belirlenmiştir. Şekil $5 b, 5 d$ ve $5 f^{\prime}$ de plaka eninin, $L_{p}=1$ 'in $3 / 4$ 'ü için silindir çiftinin ara bölgesinde oluşan girdapların şiddetini azaltmada kontrol elemanı olarak sadece delikli dış silindir kullanımı durumunda elde edilen girdap şiddeti değeri ile hibrit kontrol elemanın kullanılması durumunda elde edilen girdap şiddeti değerlerinin aynı olduğu belirlenmiştir. Girdap eş düzey eğrilerine göre girdap şiddetini azaltmada sadece delikli silindir kullanımı ile plaka en 
değeri $\mathrm{L}_{\mathrm{p}}=1$ 'in 3/4'ü kullanılarak oluşturulan hibrit kontrol elemanın girdap şiddetlerini azaltmada aynı etkiye sahip olduğu, plaka en değeri $\mathrm{L}_{\mathrm{p}}=1$ 'in ise en etkili parametre olduğu belirlenmiştir. Hibrit kontrol elemanın her iki plaka en değeri, $\mathrm{L}_{\mathrm{p}}$ için türbülans istatistik değerlerini azaltması beklenmektedir.

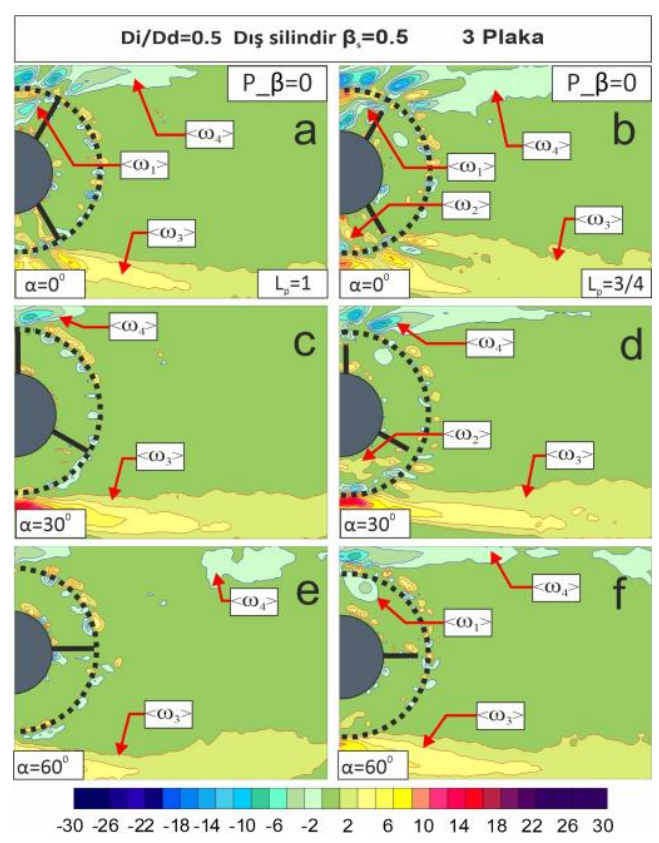

Şekil 5. Çap oranının, $D_{i} / D_{d}=0.5$, diş silindir geçirgenlik oranının, $\beta_{s}=0.5$, plaka geçirgenlik oranının, $\beta_{p}=0$, plakalar arası açının, $\theta=120^{\circ}$, plaka eninin $L_{p}=1$ ve $L_{p}=1$ 'in 3/4'ü olduğu durumda farklı plaka-akış açısı, $\alpha$ değerleri zaman ortalama girdap eş düzey eğrileri, $<\omega>$.

Şekil 6'daki grafikte çap oranı, $\mathrm{D}_{\mathrm{i}} / \mathrm{D}_{\mathrm{d}}=0.5$, dış silindir geçirgenlik oranı $\beta_{\mathrm{s}}=0.5$ ve plaka geçirgenlik oranı, $\beta_{\mathrm{p}}=0$ için iç silindir ile dış silindir arasında kalan bölgedeki Türbülans Kinetik Enerji gerilmelerinin maksimum değerlerinin plaka-akış açısı, $\alpha$ değerleri ile değişimi görülmektedir. Grafikte plaka eni, $\mathrm{L}_{\mathrm{p}}=1$ ve $\mathrm{L}_{\mathrm{p}}=1$ 'in $3 / 4$ ' $\mathrm{u}$ için elde edilen sonuçlar karşılaştırılmıştır. Akış alanı içerisinde sadece yalın silindir bulunması durumunda elde edilen maksimum TKE değeri grafikte gösterilmemiş olup değeri 0.44 olarak belirlenmiştir. Bu değer yalın silindir etrafında kontrol elemanı olarak sadece delikli dış silindir kullanıldığı durumda 0.03 değerine düşmektedir. Üç plakadan oluşan hibrit kontrol elemanı kullanılması durumunda plakaakış açısı, $\alpha=0^{\circ}$ için maksimum TKE değeri 0.033 değerlerine artış göstermiştir. Artan plaka-akış açısı değeri ile $\alpha=60^{\circ}$ için maksimum TKE değeri tekrar sadece delikli silindir kullanıldığı durumda elde edilen 0.03 değerine düşmektedir. Ancak grafikler yorumlanırken kontrol elemanı olarak sadece delikli silindir kullanılması durumunda silindir çiftinin ara bölgesinde oluşan girdap odak noktalarının hibrit kontrol elemanı kullanıldığı zaman plaka-akış açısı $\alpha=60^{\circ}$ için oluşmadığ 1 dikkate alınmalıdır. En etkili durumun ise türbülans istatistik değerleri, akış yapısı ve girdap etkileşimleri birlikte değerlendirildiği zaman diş silindir geçirgenlik oranı $\beta_{\mathrm{s}}=0.5$ için üç plaka kullanılarak oluşturulan hibirt kontrol elemanın plaka geçirgenlik oranı, $\beta_{\mathrm{p}}=0$, plakalar arası açı değeri, $\theta=120^{\circ}$ ve plaka akış açısı, $\alpha=60^{\circ}$ için plaka eninin, $L_{p}=1$ değeri için elde edildiği belirlenmiştir. 


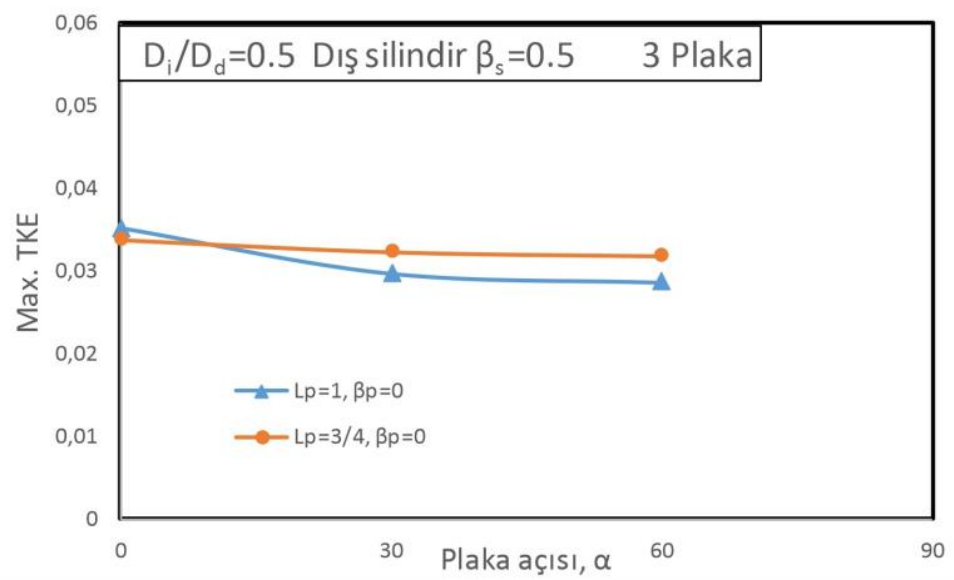

Şekil 6. Üç plaka, çap oranının, $\mathrm{D}_{\mathrm{i}} / \mathrm{D}_{\mathrm{d}}=0.5$, dış silindir geçirgenlik oranının, $\beta_{\mathrm{s}}=0.5$, plaka geçirgenlik oranının, $\beta_{p}=0$ ve plakalar arası açı, $\theta=120^{\circ}$ için plaka eninin $L_{p}=1$ ve ve $L_{p}=1$ 'in 3/4’ü olması durumunda maksimum TKE değerinin plaka-akış açısı, $\alpha$ ile değişimi.

\section{Sonuçlar}

Yalın silindir etrafinda kontrol elemanı olarak hem delikli silindir hem de hibrit kontrol elemanı kullanıldığı zaman elde edilen maksimum TKE değerlerinin plaka-akış açısı, $\alpha=60^{\circ}$ için maksimum TKE değerlerinin birbirine yakın olduğu belirlenmiştir. Ancak silindir çiftinin ara bölgesinde oluşan akış yapısı ve hem de türbülans istatistik değerleri birlikte incelendiği zaman delikli dış silindirin kontrol elemanı olarak kullanılmasının silindir çiftinin ara bölgesinde oluşan girdapları önlemede etkili olamadığı belirlenmiştir. Hibrit kontrol elemanının akış yapısını kontrol etmede etkili olduğu sirkülasyon odak noktalarının oluşmasını engellediği belirlenmiştir. Silindir çiftinin ara bölgesinde hem Türbülans istatistik değerleri hem de oluşan akış yapısı birlikte incelendiği zaman en etkili parametrenin plaka açısı, $\theta=120^{\circ}$ değerinde, plaka geçirgenlik oranının $\beta_{\mathrm{p}}=0$ değeri için plaka-akış açısı, $\alpha=60^{\circ}$ için plaka eninin, $\mathrm{L}_{\mathrm{p}}=1$ olduğu belirlenmiştir. Sonuç olarak çalışma sonucunda elde edilen optimum değerler için hibrit kontrol cihazının yalın silindirin ard izinde daimi olmayan akış yapısını kontrol etmede başarılı olduğu belirlenmiştir. $\mathrm{Bu}$ yöntemin akış kontrolündeki başarısı ile küt cisimler etrafındaki akış yapısının kontrolü konusunda kullanılan pasif kontrol yöntemlerine bir yenisi eklenmiştir.

\section{Referanslar}

[1] Blevins, R., 2001, “Flow-induced vibration”. Krieger Publishing Co., Malabar, Florida.

[2] Bruneau C. H., Mortazavi, I., "Control of Vortex Shedding around a Pipe Section Using a

[3] Porous Sheath". International Journal of Offshore and Polar Engineering Volume 16, Issue 2, June 2006.

[4] Lee T., Ko L. S. 2009. "PIV Investigation of Flowfield behind Perforated Gurney-Type Flaps”, Exp Fluids 46, 1005-1019 
[5] Choi, H., Jeon, W., Kim, J. 2008. "Control of flow over a bluff body”, Annu Rev Fluid Mech, $40,113-139$

[6] Galvao, R., E. Lee, D. Farrell, F. Hovera, M. Triantafyllou, N. Kitney, \& P. Beynet. 2008. "Flow control in flow-structure interaction", Journal of Fluids and Structures, 24, 1216-1226

[7] ROSHKO, A. 1955 On the wake and drag of bluff bodies. J. Aero. Sci. 22, 124-32.

[8] WIESELSBERGER, C. 1921 Neuere Feststellungen iiber die Gesetze des Fliissigkeits- und [ Luftwiderstands. Phys. 2. 22, 321-8.

[9] Adrian, R. J., (1991). Particle-imaging Techniques For Experimental Fluid Mechanics, Annual Review of Fluid Mechanics.

[10] Westerweel, J., (1993). Digital Particle Image Velocimetry, Theory and Application, Delft University Press.

[11] Durhasan, T., Pinar, E., Ozkan, G.M., Aksoy, M.M., Akilli, H., Sahin, B., (2018). "PIV measurement downstream of perforated cylinder in deep water", European Journal of Mechanics - B/Fluids, Volume 72, 225-234,

[12] Durhasan, T., Pinar, E., Ozkan, G.M., Akilli, H., Sahin, B., (2019). "The effect of shroud on vortex shedding mechanism of cylinder", Applied Ocean Research, Volume 84, 51-61.

\section{TEŞEKKÜR}

Bu çalışma TÜBİTAK tarafindan 114R087 no'lu proje kapsamında desteklenmiştir. 